Revista Destaques Acadêmicos, Lajeado, v. 12, n. 3, 2020. ISSN 2176-3070

DOI: http://dx.doi.org/10.22410/issn.2176-3070.v12i3a2020.2440

http://www.univates.br/revistas

\title{
AVALIAÇÃO DA QUALIDADE DO LEITE IN NATURA DE PRODUTORES RURAIS DO VALE DO TAQUARI EM DIFERENTES ESTAÇÕES DO ANO
}

\author{
Camila Pruana Schmidt ${ }^{1}$, Gabriela Kniphoff da Silva Lawisch², \\ Mônica Jachetti Maciel ${ }^{3}$
}

Resumo: Devido ao alto valor nutritivo, o leite é um importante alimento na dieta humana, contendo várias enzimas naturais, ácidos graxos, vitaminas e minerais. Com a mudança das estações do ano e, consequentemente, da temperatura, os animais sofrem alterações hormonais que alteram a qualidade do leite produzido. O objetivo deste trabalho é avaliar a qualidade do leite cru, realizando análises físico-químicas e microbiológicas, como crioscopia, acidez, $\mathrm{pH}$, teste de alizarol, contagem de aeróbios mesófilos, psicrotróficos, termotolerantes e coliformes totais. As coletas foram realizadas em diferentes estações, em agosto e outubro, sendo meses com temperaturas amenas e elevadas, respectivamente. Não foi observada diferença entre os resultados obtidos nas análises realizadas em diferentes estações, sendo assim as alterações de temperatura não tiveram interferência na qualidade do leite cru deste estudo.

Palavras-chave: Análises. Alimento. Leite cru. Normativas. Contaminação.

\section{INTRODUÇÃO}

O leite é considerado um dos mais nobres alimentos, por sua composição rica em proteína, gordura, carboidratos, sais minerais e vitaminas (VENTURINI et al., 2007). Segundo a Instrução Normativa $n^{\circ}$ 62/2011, do Ministério da Agricultura, Pecuária e Abastecimento (MAPA) entende-se por leite "o produto oriundo da ordenha completa e ininterrupta, em condições de higiene, de vacas sadias, bem alimentadas e descansadas" (BRASIL, 2011).

1 Biomédica, formada pela Universidade do Vale do Taquari- Univates, Lajeado, RS, Brasil. E-mail: camila.schmidt@universo.univates.br

2 Biomédica, mestre, professora da Universidade do Vale do Taquari- Univates, Lajeado, RS, Brasil. E-mail: gkdsilva@univates.br

3 Bióloga, doutora, professora da Universidade do Vale do Taquari- Univates, Lajeado, RS, Brasil. E-mail: monicajm@univates.br 
O sistema agroindustrial do leite, com sua enorme importância social, representa uma grande fonte de renda para o país. A atividade é praticada em todo o território nacional, e somente na produção primária gera milhões de empregos e agrega o valor da produção agropecuária nacional. De acordo uma pesquisa publicada pelo Instituto Brasileiro de Geografia e Estatística (IBGE), a produção de leite brasileira no último trimestre de 2017 foi de 6 bilhões de litros, e no Rio Grande do Sul essa produção equivaleu aproximadamente a 912 milhões de litros de leite (IBGE, 2017).

A qualidade da matéria-prima é um dos maiores obstáculos no desenvolvimento da indústria de laticínios no Brasil (VILELA et al., 2002). A prevenção de adulterações do produto in natura contra fraudes baseia-se na determinação da acidez, índice crioscópico, densidade, percentual de gordura e extrato seco desengordurado. A contagem global de microrganismos aeróbios mesófilos é um indicador de qualidade microbiológica do produto, relacionada às práticas higiênicas da ordenha e transporte (BRASIL, 2011).

Um estudo realizado por Nörnberg et al. (2009) mostra a importância de avaliações microbiológicas no leite cru refrigerado, com o resfriamento do leite nas propriedades rurais se evita a proliferação de microrganismos aeróbios mesófilos, que necessitam de temperaturas mais elevadas. Os mesófilos provem desde a má higiene até condições inapropriadas de armazenamento, podendo causar acidificação do leite.

Coliformes totais e termotolerantes são encontrados no intestino de animais mamíferos, água contaminada, solo e plantas, sendo formado por diferentes gêneros de bactérias. Com a capacidade de fermentar a lactose, produzem gás, ácido lácteo e outros gases orgânicos, para a proliferação, esse grupo de bactérias necessita de uma temperatura elevada, entre 30 e $37^{\circ} \mathrm{C}$ para os coliformes totais, e em torno de $45^{\circ} \mathrm{C}$ para os termotolerantes. Esses microrganismos são eliminados quando realizada uma pasteurização eficiente (TRONCO, 2010).

Os psicotróficos são microrganismos com capacidade de se desenvolver mesmo em temperaturas amenas, abaixo de $7{ }^{\circ} \mathrm{C}$, por si não representam um problema grave para indústria, pois submetidos a tratamentos térmicos são eliminados. Porém, são capazes de produzir enzimas proteolíticas termorresistentes que apresentam efeitos deteriorantes, as quais mantêm sua atividade mesmo após tratamentos térmicos, como o Ultra Alta Temperatura (UAT). Essas enzimas podem afetar o sabor e odor, e o tempo de vida comercial do produto (NÖRNBERG et al., 2009).

Segundo um estudo realizado por Jacomé (2012), pôde-se observar diferença significativa em alguns parâmetros analisados em diferentes estações do ano. Em períodos chuvosos, por exemplo, as vacas ficam com mais sujidades, trazendo mais contaminação para ordenha, resultando em aumento de contagem de microrganismos contaminantes no leite. Outro parâmetro observado pelo mesmo estudo é a mudança da qualidade quanto aos padrões 
físico-químicos, o qual é interferido por nutrição dos animais e estresse térmico, visto que nos períodos mais quentes a qualidade do leite é inferior comparando com épocas mais frias.

Considerando o exposto, o presente trabalho objetivou avaliar a qualidade físico-química e microbiológica do leite cru de propriedades rurais do Vale do Taquari-RS, em diferentes estações do ano.

\section{METODOLOGIA}

As amostras foram coletadas nos meses de agosto e outubro de 2018, um período de temperaturas mais baixas, e outro, temperaturas mais amenas, respectivamente. As coletas foram realizadas em tanques resfriadores de leite de produtores rurais do Vale do Taquari-RS, totalizando oito propriedades. Juntamente à coleta, foi entregue um termo de compromisso para os produtores, com a explicação dos procedimentos a serem realizados e responsabilidade de sigilo dos resultados.

As coletas foram feitas pelas pesquisadoras em potes estéreis, sendo armazenadas em caixa de isopor até os laboratórios de Ensino de Microbiologia da Univates, e Físico-químico de uma empresa de laticínios, para realização das análises em até 24 horas após a coleta.

Para as análises microbiológicas de coliformes totais e termotolerantes, foi usada a técnica de Número Mais Provável (NMP), que consiste em dois testes, um presuntivo e outro confirmativo, para o teste presuntivo, utilizando meio Lauryl Triptose Broth (OXOID®) em concentração dupla em concentração simples, todos incubados em estufa bacteriológica a $35 \pm 2{ }^{\circ} \mathrm{C}$ por até 48 horas, após, nos tubos que apresentaram formação de gás, foi transferido uma alçada para caldo Verde brilhante para cofirmação de presença de coliformes totais e uma alçada para o caldo EC para confirmação de presença de coliformes termotolerantes, foi verificado o NMP de acordo com a tabela do Manual Analítico Bacteriológico (FOOD AND DRUG ADMINISTRATION, 2017).

Realizou-se também a diluição decimal com o intuito de verificar as bactérias mesófilos e psicrotróficas, em meio de cultura ágar PCA, após a solidificação desta cultura, as placas foram incubadas em estufa bacteriológica a $35 \pm 2{ }^{\circ} \mathrm{C}$ por 48 horas para mesófilos e para psicrotróficos por 15 dias em geladeira a $7 \pm 2{ }^{\circ} \mathrm{C}$. Para as contagens, foram utilizadas placas que continham uma faixa de 30 a 300 colônias.

As análises físico-químicas foram realizadas através de crioscopia, pelo método de congelamento, utilizando um crioscópio eletrônico; $\mathrm{pH}$, com pHmetro eletrônico; acidez, por titulação utilizando fenolftaleína como indicador e titulado com solução Dornic e alizarol, feito com visualização de formação de grumos, onde se utiliza a solução de Alizarina.

Os dados foram analisados de acordo com a estatística descritiva. 


\section{RESULTADOS E DISCUSSÃO}

Foram coletadas e analisadas oito amostras em cada período. As tabelas apresentam os resultados referentes às análises físico-químicas e microbiológicas relacionadas aos leites analisados. Na Tabela 1, estão os resultados dos parâmetros físico-químicos e microbiológicos relativo à primeira amostragem realizada no mês de agosto. A Tabela 2 apresenta os mesmos parâmetros sendo estes referentes a segunda amostragem, do mês de outubro. Foram considerados os limites máximos estabelecidos pela Instrução Normativa (IN) n 76/2018 (BRASIL, 2018) para o leite cru refrigerado.

Tabela 1 - Resultados dos parâmetros físico-químicos e microbiológicos referentes a primeira amostragem (agosto) dos oito produtores leiteiros, de em um município do Vale do Taquari - RS

\begin{tabular}{ccccccccc}
\hline Amostra & $\begin{array}{c}\text { Crioscopia } \\
\left({ }^{\circ} \mathrm{H}\right)\end{array}$ & $\begin{array}{c}\text { Acidez } \\
\left({ }^{\circ} \mathrm{D}\right)\end{array}$ & $\mathrm{pH}$ & $\begin{array}{c}\text { Alizarol } \\
(\%)\end{array}$ & $\begin{array}{c}\text { Colif. Total } \\
(\mathrm{NMP} / \\
\mathrm{mL})\end{array}$ & $\begin{array}{c}\text { Colif. Termo } \\
(\mathrm{NMP} / \mathrm{mL})\end{array}$ & $\begin{array}{c}\text { Mesóflios } \\
\text { UFC } / \mathrm{mL}\end{array}$ & $\begin{array}{c}\text { Psicrotróficos } \\
\text { UFC } / \mathrm{mL}\end{array}$ \\
\hline 1 & $-0,530$ & 14,9 & 6,74 & 76 & $>1100$ & 1100 & $5,6 \times 10^{4}$ & $4,9 \times 10^{5}$ \\
2 & $-0,526$ & 16,0 & 6,73 & 78 & $>1100$ & 210 & $1,0 \times 10^{5}$ & $8,0 \times 10^{4}$ \\
3 & $-0,538$ & 15,5 & 6,72 & 74 & 1100 & 1100 & $1,1 \times 10^{4}$ & $3,0 \times 10^{4}$ \\
4 & $-0,539$ & 16,0 & 6,72 & 80 & 160 & 160 & $2,0 \times 10^{3}$ & 0 \\
5 & $-0,547$ & 15,1 & 6,85 & 76 & 120 & 120 & $2,0 \times 10^{3}$ & $1,6 \times 10^{5}$ \\
6 & $-0,540$ & 15,7 & 6,8 & 76 & 93 & 93 & $2,0 \times 10^{5}$ & $2,0 \times 10^{4}$ \\
7 & $-0,526$ & 16,2 & 6,78 & 72 & 290 & 290 & $3,1 \times 10^{4}$ & $5,0 \times 10^{5}$ \\
8 & $-0,539$ & 15,8 & 6,81 & 82 & 160 & 160 & $3,5 \times 10^{4}$ & 0 \\
\hline \multirow{2}{*}{ Padrões } & $0,555 \mathrm{a}$ & $14,0 \mathrm{a}$ & $6,60 \mathrm{a}$ & $72 \%$ & - & - & $3 \times 10^{5}$ & $1 \times 10^{6 *} \mathrm{UFC} /$ \\
& $-0,530{ }^{\circ} \mathrm{H}$ & $18{ }^{\circ} \mathrm{D}$ & 6,80 & $\mathrm{v} / \mathrm{v}$ & - & - & $\mathrm{UFC} / \mathrm{mL}$ & $\mathrm{mL}$ \\
\hline
\end{tabular}

*Psicrotróficos não têm padrões na $\mathrm{IN}^{\circ}$ 76/2018, então se utilizou o estudo de Nörnberg (2009).

Tabela 2 - Resultados dos parâmetros físico-químicos e microbiológicos referentes a segunda amostragem (outubro) dos oito produtores leiteiros, de em um município do Vale do Taquari - RS

\begin{tabular}{ccccccccc}
\hline Amostra & $\begin{array}{c}\text { Crioscopia } \\
\left({ }^{\circ} \mathrm{H}\right)\end{array}$ & $\begin{array}{c}\text { Acidez } \\
\left({ }^{\circ} \mathrm{D}\right)\end{array}$ & $\mathrm{pH}$ & $\begin{array}{c}\text { Alizarol } \\
(\%)\end{array}$ & $\begin{array}{c}\text { Coli. Total } \\
(\mathrm{NMP} / \mathrm{mL})\end{array}$ & $\begin{array}{c}\text { Coli. Termo } \\
(\mathrm{NMP} / \mathrm{mL})\end{array}$ & $\begin{array}{c}\text { Mesóflios } \\
\mathrm{UFC} / \mathrm{mL}\end{array}$ & $\begin{array}{c}\text { Psicrotróficos } \\
\mathrm{UFC} / \mathrm{mL}\end{array}$ \\
\hline 1 & $-0,529$ & 14,8 & 6,82 & 74 & $>1100$ & 1100 & $3,3 \times 10^{4}$ & $2,1 \times 10^{5}$ \\
2 & $-0,540$ & 16,3 & 6,81 & 80 & 1100 & 460 & $5,4 \times 10^{4}$ & $2,0 \times 10^{3}$ \\
3 & $-0,536$ & 15,3 & 6,82 & 72 & $>1100$ & 1100 & $2,4 \times 10^{4}$ & 0 \\
4 & $-0,538$ & 15,3 & 6,86 & 80 & 160 & 160 & $2,1 \times 10^{4}$ & $2,0 \times 10^{3}$ \\
5 & $-0,528$ & 15,2 & 6,84 & 78 & 75 & 75 & $<300$ & $2,0 \times 10^{4}$ \\
6 & $-0,531$ & 15,5 & 6,86 & 80 & 150 & 150 & $4,3 \times 10^{4}$ & $9,0 \times 10^{3}$ \\
7 & $-0,528$ & 16,4 & 6,82 & 74 & 150 & 150 & $5,7 \times 10^{4}$ & $6,8 \times 10^{4}$ \\
8 & $-0,533$ & 16,0 & 6,84 & 82 & $>1100$ & 1100 & $8,4 \times 10^{4}$ & $8,0 \times 10^{3}$ \\
\hline \multirow{2}{*}{ Padrões } & $-0,555 \mathrm{a}$ & $14,0 \mathrm{a}$ & $6,60 \mathrm{a}$ & $72 \%$ & - & - & $3 \times 10^{5}$ & $1 \times 10^{6 *} \mathrm{UFC} /$ \\
& $-0,530{ }^{\circ} \mathrm{H}$ & $18^{\circ} \mathrm{D}$ & 6,80 & $\mathrm{v} / \mathrm{v}$ & - & & $\mathrm{UFC} / \mathrm{mL}$ & $\mathrm{mL}$ \\
\hline
\end{tabular}

*Psicrotróficos não têm padrões na $\mathrm{IN}^{\circ}$ 76/2018, então se utilizou o estudo de Nörnberg (2009). 
Na comparação do mês mais chuvoso e frio (primeira coleta- agosto) com o mês de temperaturas amenas (segunda coleta- outubro), as análises microbiológicas tiveram uma melhora, ou seja, diminuiu o crescimento microbiológico nos resultados de coliformes totais e coliformes termotolerantes, visto que decaiu o número de $\mathrm{NMP} / \mathrm{mL}$. Porém, da mesma forma, os números são altos, indicando que esses resultados podem estar associados à sujidade em que os animais entram nos estábulos, tendo uma maior contaminação inicial do leite, isso quando não é feita a limpeza correta dos úberes. Presença de coliformes totais e termotolerantes são indicadores de contaminações do ambiente e de fezes, evidenciando uma contaminação da matéria-prima de vários produtos lácteos. Em um estudo feito por Farias (2014), o número de coliformes totais e termotolerantes foram bem expressivos, com todos os resultados fora dos limites estipulados por lei, ressaltando que as condições de ordenha não são adequadas, assim como a higiene dos funcionários.

As bactérias mesófilas nos dois períodos tiveram as amostras dentro dos padrões fixados pela IN n 76 de 2018 (BRASIL, 2018) e a comparação entre as estações não houve diferença preocupante, pois quatro das oito amostras diminuíram a contagem, e outras quatro aumentaram. Esses resultados podem estar relacionados diretamente com uma contaminação inicial por falta de refrigeração imediata ou por parte dos manipuladores, onde a falta de higiene é o principal fator interferente. É necessário que o leite seja resfriado logo após a ordenha, para que esse tipo de bactéria não se prolifere, visto que todas as coletas foram feitas em sistemas com ordenhas mecânicas.

Um estudo feito por Jacomé (2012) demonstrou que a contagem bacteriana total (CBT) é afetada pelos sistemas de produção, estando relacionada com o tipo de estrutura usada para alimentação dos animais. Em épocas mais chuvosas, os animais em sistemas extensivos ou semiconfinados chegam ao local da ordenha com mais sujidades nos úberes, aumentado a CBT. As melhores medidas para controle de CBT consistem na redução da carga microbiana inicial, sendo necessário um cuidado especial na hora de lavagem dos úberes, ou seja, sistemas confinados tendem a ter melhores resultados para CBT, uma vez que os melhores padrões são encontrados nas épocas frias.

Silva et al. (2010), no estado de São Paulo, verificaram interferência das estações e tipo de ordenha utilizada, foram observados valores de CBT mais elevados em períodos secos, e a contagem de psicotróficos foi maior em períodos chuvosos. Dessa forma, sugere-se que esses microrganismos não têm relação direta com o meio ambiente, visto que os resultados de CBT estavam todos acima dos padrões de legislação, podendo estar associados à falta de higiene dos manipuladores.

A contagem microbiológica de psicrotróficos, apesar de não ser uma análise exigida pelo MAPA, é de grande importância para determinação da qualidade do leite. As bactérias em si, na sua grande maioria, são eliminadas quando o leite passa pelo processo de pasteurização, porém, esses 
microrganismos são capazes de produzir enzimas lipolíticas e proteolíticas termorresistentes, que mantêm sua atividade após a pasteurização ou até mesmo, após o tratamento de Ultra Alta Temperatura (UAT). O padrão para a contagem de psicrotróficos sugeridos pelo autor é de $1,0 \times 10^{6} \mathrm{UFC} \mathrm{mL}^{-1}$, sendo que valores superiores podem acarretar em gelatinização do leite UAT, além de alterações no sabor do leite (NÖRNBERG et al., 2009). Todas as amostras analisadas nos dois períodos se encontraram dentro dos padrões sugeridos por Nörnberg et al. (2009), demonstrando que a contaminação por esse tipo de bactéria está controlada, acarretando em melhor qualidade de matéria prima para produtos UAT.

Nas oito amostras analisadas, a acidez da segunda coleta diminuiu em quatro amostras, segundo Gonzalez et al. (2004), em um estudo realizado na bacia leiteira de Pelotas-RS, a acidez diminuiu em um dos meses estudados, relacionado com o número aumentado de mastite, já Romeiro et al. (2016) observou inconformidade de $25 \%$ de suas amostras, quanto a acidez, todas estavam fora dos padrões para coliformes totais e termotolerantes, mostrando a relação da qualidade físico-química e microbiológica.

O teste de alizarol não revelou amostras em níveis de não conformidade, demonstrando que o leite analisado possui uma boa estabilidade alcoólica, porém, algumas amostras possuem alizarol mais alto, refletindo uma qualidade melhor. Romeiro et al. (2016) observou em sua pesquisa apenas uma amostra alterada no teste de alizarol, sugerindo que não houve refrigeração imediata após a ordenha.

A crioscopia se mostrou fora dos padrões em quatro amostras, duas em cada coleta, tendo uma média dos resultados na primeira coleta de $-0,536$ e $-0,533{ }^{\circ} \mathrm{H}$, sendo o padrão fixado por legislação máximo -0,530 e mínimo -0,555 ${ }^{\circ} \mathrm{H}$, esses resultados mais altos hipoteticamente podem ser provenientes de entrada de água nos tanques refreadores ou má alimentação do rebanho, os valores fora desses padrões são indicativo de fraude, sendo a mais comum, a fraude com água. Gonzalez et al. (2004) obtiveram resultados de crioscopia inalterada entre os meses estudados, tendo a média de $-0,518$, considerada fora de padrão.

\section{CONCLUSÃO}

Não foi possível observar diferenças importantes entre os meses analisados, dessa forma, as diferenças climáticas de temperatura não tiveram interferência na qualidade do leite cru, pois os meses analisados não tiveram temperaturas de extrema diferença. Mesmo assim, ressalta-se a importância de monitoramento das amostras, visando diminuir os riscos de contaminação microbiológica, para garantir melhor qualidade físico-química. 


\section{REFERÊNCIAS}

BRASIL. Ministério da Agricultura, Pecuária e Abastecimento (MAPA). Normativa n ${ }^{\circ}$ 62 de 29 de dezembro de 2011. Regulamento Técnico de Identidade e Qualidade de Leite Cru Refrigerado. Diário Oficial da União. Brasília, 29 de dezembro de 2011.

BRASIL. Ministério da Agricultura, Pecuária e Abastecimento (MAPA). Normativa n ${ }^{\circ}$ 76 de 26 de novembro de 2018. Regulamento Técnico de Identidade e Qualidade de Leite Cru Refrigerado. Diário Oficial da União. Brasília, 30 de novembro de 2018.

FARIAS, C.P. Qualidade microbiológica do leite cru in natura, leite cru refrigerado e leite pasteurizado comercializados na região de Uberlândia, MG. Revista Verde de Agroecologia e Desenvolvimento Sustentável. v.9. n.4, p. 250 - 254, out-dez, 2014.

FOOD AND DRUG ADMINISTRATION. Bacteriological Analytical Manual (BAM). Appendix 2: Most Probable Number from Serial Dilutions (2017). Disponível em: <https://www.fda.gov / food/laboratory-methods-food/bam-appendix-2-mostprobable-number-serial-dilutions\#table1>. Acesso em: 14 out. 2020.

GONZALEZ, H. L. et al. Avaliação da qualidade do leite na bacia leiteira de Pelotas, RS. Efeito dos meses do ano. Revista Bras. Zootec [online]. Disponivel em: http:/ / dx.doi.org/10.1590/S1516-35982004000600020. v.33, n.6, p.1531-1543, 2004.

IBGE. Pesquisa Trimestral do Leite. Quantidade de leite cru adquirido e industrializado no mês e no trimestre (Mil Litros), $4^{\circ}$ trimestre 2017. Disponível em: www.ibge.gov.br/estatisticas-novoportal/economicas/agricultura-e-pecuaria/9209pesquisa-trimestral-do-leite.html?edicao=20519\&t=destaques. Acesso em 20 maio.2018.

JACOMÉ, D.C. Avaliação da qualidade do leite cru em diferentes sistemas de produção e épocas do ano. 2012. Dissertação (Mestrado em Profissional em Zootecnia) - Universidade Federal de Viçosa, Viçosa, 12 de jul. 2012.

NÖRNBERG, M.F.B.L.; TONDO, E.C.; BRANDELLI, A. Bactérias psicrotróficas e atividade proteolítica no leite cru refrigerado. Acta Scientiae Veterinariae, v.37, n.2, p.157-163, 2009.

ROMEIRO, S.S; et al. Análise bacteriológica e físico-química de Leite cru comercializado informalmente em Teixeira de Freitas- BA. Ciencia e Tecnologia: FATEC-JB. v.8, n. especial, 2016.

SILVA, M.A.P. et al. Variação da qualidade do leite cru refrigerado em função do período do ano e do tipo de ordenha. Rev. Inst. Adolfo Lutz. São Paulo, v. 69, n.1,2010.

TRONCO, V.M. Manual para inspeção da Qualidade do leite. 4.ed. Santa Maria: editoraUFSM, 2010. 
VENTURINI, S.K.; SARCINELLI, F.M.; SILVA, L.C. Características do Leite. Espirito Santo, 2007. Disponível em: http:/ /agais.com/telomc/b01007_caracteristicas_leite.pdf

VILELA, D.; LEITE, J.L.B.; RESENDE, J.C. Políticas para o leite no Brasil: passado presente e futuro. In: Santos, G. T.; Jobim, C. C.; Damasceno, J. C. SulLeite Simpósio sobre Sustentabilidade da Pecuária Leiteira na Região Sul do Brasil, 2002, Maringá. Anais... Maringá: UEM/CCA/DZO-NUPEL, 2002. 